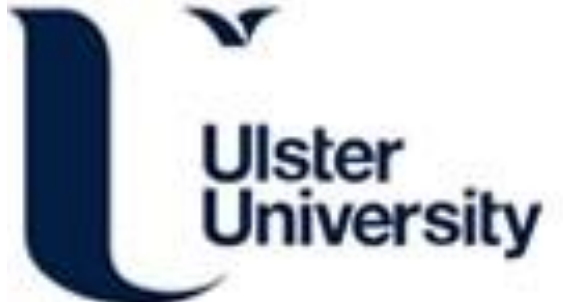

\section{'The care circle consists of me.' Loneliness and social isolation for older male spousal care-givers.}

Fee, A., Mcllfatrick, S. J., \& Ryan, A. (2021). 'The care circle consists of me.' Loneliness and social isolation for older male spousal care-givers. A qualitative study. Ageing and Society, 1-18.

https://doi.org/10.1017/S0144686X21000854

Link to publication record in Ulster University Research Portal

Published in:

Ageing and Society

Publication Status:

Published online: 08/07/2021

DOI:

10.1017/S0144686X21000854

Document Version

Publisher's PDF, also known as Version of record

\section{General rights}

Copyright for the publications made accessible via Ulster University's Research Portal is retained by the author(s) and / or other copyright owners and it is a condition of accessing these publications that users recognise and abide by the legal requirements associated with these rights.

\section{Take down policy}

The Research Portal is Ulster University's institutional repository that provides access to Ulster's research outputs. Every effort has been made to ensure that content in the Research Portal does not infringe any person's rights, or applicable UK laws. If you discover content in the Research Portal that you believe breaches copyright or violates any law, please contact pure-support@ulster.ac.uk. 


\title{
'The care circle consists of me.' Loneliness and social isolation for older male spousal care-givers. A qualitative study
}

\author{
Anne Fee ${ }^{1 *}$ (D), Sonja Mcllfatrick ${ }^{1}$ (D) and Assumpta Ryan ${ }^{2}$ (D) \\ ${ }^{1}$ School of Nursing and Institute of Nursing and Health Research, Ulster University, Newtownabbey, UK \\ and ${ }^{2}$ School of Nursing and Institute of Nursing and Health Research, Ulster University, Londonderry, UK \\ ${ }^{*}$ Corresponding author. Email: A.fee@ulster.ac.uk
}

(Accepted 11 May 2021)

\begin{abstract}
Whilst loneliness and social isolation amongst older care-givers are becoming increasingly recognised, little is known about how these concepts impact on specific sub-groups of care-givers, such as older males. In the current study, we aimed to gain a better understanding of the experiences of loneliness and social isolation amongst older spousal male care-givers. Semi-structured interviews were undertaken with 24 participants, caring for a spouse/partner with a long-term chronic condition. After thematic analysis of the data, three themes were identified: dwindling social interactions, loneliness in the spousal relationship, and living with loneliness and social isolation. Study findings suggest that opportunities for social interactions gradually 'dwindled' due to a reluctance by older male care-givers to leave their spouse/partner at home alone, to accept offers of help or respite, or to attend social events without their spouse/partner. Consequently, social isolation increased. Feelings of physical and emotional loneliness were evident, and the loss of spousal companionship (such as loss of conversation and shared interests) increased loneliness. Individualised coping strategies were adopted including focusing on moments of positivity, talking to others and using prescribed medication. Findings provide insight into the experience of loneliness and social isolation for many older male spousal caregivers. This may facilitate a better understanding of older male care-givers' support needs in addressing loneliness and social isolation, and should help to inform the development of targeted support services for this population.
\end{abstract}

Keywords: care-giver; loneliness; social isolation; male; masculinity; spousal; support

\section{Introduction}

Loneliness and social isolation are growing international public health concerns and have been recognised in research with older people as a risk factor for poorer physical and mental health and mortality (Steptoe et al., 2013; Holt-Lunstad et al., 2015; Valtorta et al., 2016; Courtin and Knapp, 2017; Gale et al., 2017). Although social isolation and loneliness can occur within any age group, older people may be

(c) The Author(s), 2021. Published by Cambridge University Press 
particularly at risk due to declining health; changes in family structure; the death of spouses, friends and family; and limited social or economic opportunities (Cohen-Mansfield et al., 2016; Brodsky et al., 2017).

According to De Jong Gierveld et al. (2006), loneliness occurs when an individual perceives a mismatch between their desired and achieved level of social interaction. Age UK (2018) estimated that the number of older people experiencing loneliness had increased by 49 per cent in the United Kingdom (UK) over the past decade and this is set to reach over two million by 2025. A similar picture exists across Europe. For example, a survey of late-life loneliness across 11 European countries revealed a level of 'quite severe loneliness' in 30-55 per cent of older people in eastern Europe (Hansen and Slagsvold, 2016).

Social isolation has been defined as: 'an objective measure reflecting an individual's lack of contacts or ties with others, such as family, friends, acquaintances and neighbours' (De Jong Gierveld et al., 2006, in Cotterell et al., 2018). Social isolation has been shown as a predictor for loneliness amongst older care-givers (Victor et al., 2020). It has also been associated with specific chronic illnesses such as dementia (Kuiper et al., 2015), stroke and cardiovascular disease (Valtorta et al., 2016), and mental health issues including depression (Matthews et al., 2016).

In western society, even though numbers of female care-givers outnumber males in the under 65 age range, in older age groups $(85+)$ evidence would indicate that males are increasingly assuming a primary care-giving role (Family Caregiver Alliance, 2019). However, despite indications that men are becoming more visible as care-givers (Schwartz and McInnis-Dittrich, 2015), it has been suggested that they have a limited awareness of support services (Milligan and Morbey, 2013, 2016) and that their support needs are neglected (Sharma et al., 2016; Dickinson et al., 2017).

Research has demonstrated gender-based differences in the experience and impact of loneliness and social isolation (Yang et al., 2013; Zebhauser et al., 2014; Courtin and Knapp, 2017; Gale et al., 2017), although findings have been inconsistent. Whilst some studies, such as Gale et al. (2017), identified that older women tended to be lonelier and more socially isolated than older men, others argued that social isolation negatively impacted more on older men than older women (Independent Age and the International Longevity Centre UK, 2014); and that the impact of loneliness on all-cause mortality was greater for men than women (Rico-Uribe et al., 2018). However, it has also been shown that gender distribution in research on care-giving, and on loneliness and social isolation among older adults, is skewed towards the female population (Poscia et al., 2017; Fakoya et al., 2020).

The occurrence of the global pandemic - Coronavirus disease 2019 (COVID-19) has resulted in an urgent need to recognise the vital role played by care-givers, and to determine their support needs. Restrictions imposed by global governments to limit the spread of the virus mean that many care-givers are providing care beyond their usual caring role (Cohen et al., 2020; Phillips et al., 2020); and have led to selfisolation which has been found to amplify loneliness and intensify social isolation (Alzheimer's Association, 2020). 
The dearth of literature about experiences of and support needs of older male care-givers is well documented (Sharma et al., 2016; Courtin and Knapp, 2017). Some existing research indicates that older male care-givers are particularly vulnerable to loneliness and social isolation (Milligan and Morbey, 2013; Nel and Board, 2019). Given these suggestions along with the reported increase in numbers of older male care-givers, it is important to identify and understand factors that contribute to loneliness and social isolation in this population in order to inform development of targeted future support. For the purpose of this study, 'older care-givers' are defined as care-givers over 65 years of age as this is the definition of 'older' in western societies (World Health Organization, 2014).

The study aim is to gain an understanding of the impact, if any, of loneliness and social isolation on older male care-givers, caring for a spouse/partner with a longterm chronic condition.

\section{Methods}

\section{Design}

The current study was part of a larger study conducted in a region in the UK which aimed to examine the support needs of older male care-givers (Fee et al., 2020a). Findings of the larger study revealed that loneliness and isolation were issues for older male care-givers. The research presented in this paper reports on this specific aspect of these findings.

A qualitative exploratory approach, using thematic analysis was employed (Braun and Clarke, 2006). Previous authors have emphasised the efficacy of qualitative approaches to exploring loneliness, suggesting that, given the highly individualised experience of loneliness, qualitative data could provide deeper insights into the phenomenon than quantitative analysis (Finlay and Kobayashi, 2018). However, qualitative studies about loneliness and social isolation are sparse (Cohen-Mansfield and Eisner, 2020), as are studies exploring the experience of loneliness and social isolation with 'at-risk' groups in the population, such as unpaid care-givers (Courtin and Knapp, 2017).

\section{Sample}

A purposive sample (Silverman, 2004) was chosen for the study because a sample of a population with similar characteristics and situations was needed in order to help understand the experience (i.e. older male care-givers caring for a spouse/partner).

Recruitment of participants was undertaken in liaison with agencies within the statutory and community/voluntary sectors in a region in the UK. Inclusion criteria were: male care-givers, aged 65 years and over; primary care-giver for a chronically spouse/partner; living in the community; and ability to give informed consent. All study participants but one were married, in heterosexual relationships and the length of relationships ranged from 16 to 60 years. Chronic illnesses of the care recipients were: dementia $(\mathrm{N}=16)$, stroke $(\mathrm{N}=4)$, Parkinson's disease $(\mathrm{N}=2)$, multiple sclerosis $(\mathrm{N}=1)$ and severe epilepsy $(\mathrm{N}=1)$. Details of the participants' characteristics are in Table 1. 
Table 1. Participant characteristics

\begin{tabular}{|c|c|c|c|c|}
\hline Identifier & $\begin{array}{l}\text { Length of time } \\
\text { caring (years) }\end{array}$ & $\begin{array}{l}\text { Age of } \\
\text { care-giver }\end{array}$ & $\begin{array}{l}\text { Length of relationship } \\
\text { (years) }\end{array}$ & $\begin{array}{l}\text { Age of } \\
\text { partner }\end{array}$ \\
\hline Clive & 9 & 72 & 46 & 69 \\
\hline Simon & 13 & 75 & 52 & 75 \\
\hline Sean & 2 & 82 & 59 & 81 \\
\hline Dessie & 8 & 73 & 49 & 75 \\
\hline Jack & 4 & 68 & 39 & 66 \\
\hline Joseph & 9 & 68 & 32 & 59 \\
\hline Robert & 4 & 69 & 41 & 70 \\
\hline Gerry & 14 & 61 & 27 & 54 \\
\hline Mark & 7 & 65 & 40 & 61 \\
\hline Mike & 4 & 76 & 51 & 76 \\
\hline Ian & 22 & 70 & 42 & 65 \\
\hline Gary & 6 & 66 & 33 & 66 \\
\hline Harry & 8 & 81 & 60 & 78 \\
\hline Dan & 6 & 66 & 38 & 68 \\
\hline Paul & 3 & 81 & 54 & 78 \\
\hline Tim & 4 & 79 & 56 & 77 \\
\hline Noel & 2 & 72 & 16 & 60 \\
\hline Patrick & 15 & 73 & 37 & 70 \\
\hline Bobby & 5 & 68 & 41 & 63 \\
\hline Aidan & 6 & 70 & 48 & 69 \\
\hline Andy & 5 & 72 & 39 & 69 \\
\hline Berty & 2 & 68 & 44 & 64 \\
\hline Colin & 7 & 66 & 47 & 68 \\
\hline Alan & 4 & 83 & 58 & 83 \\
\hline
\end{tabular}

\section{Data collection}

Semi-structured interviews were undertaken with older male care-givers $(\mathrm{N}=24)$. The aim of the interviews was to gain a better understanding of older male caregivers' experiences of providing care for their spouses/partners who were living with a long-term chronic condition. Semi-structured interviews were chosen to enable a focus whilst allowing for in-depth discussion. An interview schedule (Bryman, 2015) was developed in line with the study aims, theory and a review of the literature. The interview schedule provided a broad framework in which to explore care-giving experience and coping mechanisms. The schedule was piloted with two older male care-givers, which resulted in two modifications: changing the order of some questions and including additional prompts. The schedule 
comprised broad questions about male care-givers' experiences of their care-giving role, enabling factors and perceived barriers to support with their care-giving role, coping mechanisms they used, and prompts on specific physical and emotional impacts of care-giving if they did not arise spontaneously in the discussion. Data were drawn from responses to questions or prompts about emotional aspects of the care-giving role, specifically loneliness or experiences of social isolation.

Interviews were conducted between November 2017 and January 2018, and lasted between 45 and 90 minutes. Interviews were digitally recorded (with written informed consent), and took place either in the care-giver's own home, a community venue or a local day centre. Care-givers were interviewed alone. Consent to be interviewed was obtained during the initial telephone conversation, and informed written consent was obtained before the interview commenced. Interviews were undertaken by the first author (AF), who had participated in specialised in-depth interview training.

\section{Data analysis}

Inductive thematic analysis was adopted for this phase (Braun and Clarke, 2006). The process of analysing began during data collection, as the researcher was noticing recurring themes during the interviews. Notes were made about these observations in the field notes. To develop the analytic framework further, the six steps outlined in Braun and Clarke (2006) were followed in the process of analysis: (a) familiarisation with the data, (b) generating initial codes, (c) searching for themes, (d) reviewing themes, (e) defining and naming themes, and (f) producing the report.

Interviews were transcribed verbatim, and all transcripts were read against audio recordings to ensure accuracy. After re-reading transcripts for familiarisation, line-by-line coding was employed to develop an initial coding framework, underpinned by the research aim and key literature. Initial themes were identified, and differences of opinion were discussed among the research team until consensus was reached. Key themes were then developed, refined and named. Codes were checked against data to enhance credibility (Quinn-Patton, 2002). Data were imported into NVivo 11 qualitative data analysis software (QSR International, Melbourne). Finally, an audit trail, comprising a researcher reflexive journal, and defined analytical techniques for thematic analysis, ensured dependability and confirmability (Lincoln and Guba, 1985).

\section{Ethics}

The study was granted ethical approval from OREC (UK), Ulster University School of Nursing, Research Ethics Committee and the Northern Health and Social Care Trust.

\section{Findings}

Three over-arching themes were identified from analysis of the data: (1) dwindling social interactions; (2) loneliness in the spousal relationship; and (3) living with loneliness and social isolation. These are discussed in detail below. 


\section{Theme 1: Dwindling social interactions - 'The care circle consists of me'}

All participants discussed how opportunities for social interaction had dwindled, either for them as an individual or as a couple, during the progression of the chronic illness. Several described how their social life had 'fallen away' in general terms, whereas others gave specific examples of instances when they realised that their social circumstances had changed for good and described the impact of this:

It hit me when I was invited to Russell Watson show, and at first, my friends did say 'we're going, do you think [wife] would be able to go?' I said 'no, don't worry' ... it just hit home, well that's reality ... just a fact of life that I've got to accept now, that friends will be doing their own things, I will not be included because of that reason. So, I now don't take any umbrage at that, I accept that, I understand. But, things have dwindled, for want of a better word, that's the best way I can say that. (Clive)

Even when social connections were maintained, it was noted how some illness symptoms, such as difficulty communicating or incontinence, could lead to embarrassment or discomfort for either the care recipient or their friends. This factor appeared to impact on participants' desire to accept social invitations and eventually resulted in invitations increasingly being turned down. Dan recounted a typical scenario:

When we're out with friends, which is very rare now, I hate it when a female friend says 'I'll take her to the toilet' and my brain says you don't know what you're letting yourself in for, and they will insist on doing it and I feel like saying 'no, I will do it'. (Dan)

As participants gave up sporting and other activities to enable them to remain at home, friends 'dropped away' and visitors became more and more infrequent. A small number of men explained how their only adult conversations now were with care workers or 'officials':

I don't interact with anybody other than things like this [interview] and other officials. Neighbours say 'it must be difficult' - but it's all platitudes. As I described it to somebody, I said 'it's like when you've had a death in the family, people don't know how to talk to you' and it's the same with this. (Robert)

Other participants expressed fear that something bad may happen to their spouse/ partner if they were left alone at home for any length of time. Also, when they were at home together a sense of protection underpinned their care-giving approach, as described by Jack and Harry:

I don't leave her behind for that sort of thing. If something happened, I'd be afraid if I was out and she got up to touch something, or maybe got electrocuted or hurt and wouldn't know where to turn or how to use the phone. (Jack) 
I can't let my wife go near the cooker, because she'd burn herself because of the dementia and deterioration of it. (Harry)

These sentiments were echoed by another participant who added that the point when his spouse could no longer be left at home on her own was a 'game changer', as this was the point at which he realised that their lives were curtailed, and he was becoming increasingly house-bound:

You feel alone, very alone and regardless of what are my social contacts and my sport that I was involved with, I can't do it because I'm frightened of leaving her by herself. (Berty)

Alongside this, some participants emphasised an independent approach to caregiving - either as a result of, or in spite of, dwindling social interactions. For example, if participants had grown up children or siblings, they explained that they were sometimes reluctant to verbalise the extent of their care-giving role; or there was a resistance to offers of outside help:

I'll be honest with you, my family didn't know half of the things I had to do in here. (Colin)

So really, the care circle consists of me, and then occasional participants like my sister who is very helpful when she can be, but she has her own family and so on. (Simon)

Another participant was offered the opportunity to take a break from his caregiving role by someone who would provide care for his wife. However, he refused, as he believed that he was the only person who could deal with his wife's illness symptoms:

I don't really think anything could have helped because I wouldn't have wanted anybody to sit in with me to give an hour's [respite] ... because I wanted to be there to ... I knew how to get her out of a panic attack, I could bring her out of it. (Alan)

Even though an independent approach seemed to be favoured by some, for others this was experienced as a paradoxical situation whereby men recognised that they needed support but were reluctant to accept it:

You sort of don't think you need everybody else, but it sort of builds up in your head. The things that you want to say but you can't say. (Paul)

\section{Theme 2: Loneliness in the spousal relationship - 'It was like mourning somebody and still living with them'}

The majority of participants expressed feelings of loneliness, both physically and emotionally. One commented that he may as well have been alone in the house 
as his wife always slept while they were watching television. For others, the gradual loss of conversation, which is associated with many chronic progressive illnesses, signified a loss of spousal relationship and companionship which resulted in feelings of emotional loneliness:

[Wife] doesn't talk. This is one of the first things, you know, when it really began to, sort of, bite. One of the first things that [wife] lost was the ability to talk. (Bobby)

It started off talking just nonsense, you know, and then gradually that even, that decreased. She would have said my name every so often, and she would have known the children, and would have said their names, but then the likes of that, sort of, went as well. She doesn't talk at all. There is no conversation. (Alan)

Although some men appeared to accept that this was part of the illness trajectory, others experienced distress, especially those who had been with their partner for many years (more than 40 for some). Colin described:

I felt very lonely. I think that was the real suicidal part of it, just sitting here and as I said to you, it was like mourning somebody and still living with them and that's very true. (Colin)

There was some evidence that marriage vows underpinned a sense of obligation to provide care, resulting in feelings of loss of freedom. One participant was considering placement into long-term residential care, as described:

I would be telling you a lie if the thought hadn't crossed my mind saying 'God, I didn't sign up for this', I've said that to myself, I'll be honest. I said 'God, I didn't sign up for this, have I got 20-odd years of this left in my life'? Now, you say for better for worse and all the rest, I accept that, but you don't stand there saying 'if she takes dementia, I don't want to know'. (Dan)

Similarly, Robert depicted a sense of restriction and frustration, as awareness of the permanence of his situation grew:

I mean I have to say I could live apart quite easily just so I can do something with my life. Annoying whatever way you look at it, it ain't going to get any better and I'm doing nothing, I'm getting satisfaction from nothing because I can't even do a physical job because I can't see it through. No, that's beginning to grate. (Robert)

By contrast, for other participants marriage vows were viewed in a positive light and underpinned their commitment to their spouse/partner. Small moments of positivity were sought out and served to reinforce their devotion, and as motivation for their care-giving role:

Every Saturday, I'd take her into town and have lunch. It gets her out of the house. I love to do that with her. Sometimes, you get no reaction to it, 'That's nice' or 
'That's lovely'. Those are the kinds of things that come back. I get satisfaction from that; at least you're getting her realising and thanking you for what you're doing for her. (Mike)

Mike's comments were echoed by others who were grateful for the company of their spouse/partner and appreciated the opportunity for relationship reciprocity. Consequently, the spousal bond seemed to mitigate feelings of loneliness for these participants:

Somebody said to me, 'would it have been better if [wife] had have had a heart attack and died?' I said, 'no, it wouldn't, [wife's] still there'. I suppose everybody looks at it differently. (Andy)

The closeness is still there. I always remember, when you get married, 'In sickness and in health, for richer, for poorer.' As well as that, if the shoe was on the other foot, I know she'd do it for me. (Tim)

\section{Theme 3: Living with loneliness and social isolation - 'You're not really looking for answers when you talk to people, you just want to talk'}

Having someone to talk to, and using prescribed medication were strategies adopted by some participants as a way to cope with challenges associated with their care-giving role. Several participants highlighted the benefits of having someone to talk to. As the following quote describes, sometimes this was not a pro-active strategy, rather a chance meeting with someone which acted as a trigger for them to 'unburden'. Some men recognised this as an opportunity to avail of support:

I've recently discovered an auntie; she's getting on a bit now and I was talking to her about it and we ended up having quite a long conversation. She's really good, so I could unburden. You're not really looking for answers when you talk to people, you just want to talk. (Alan)

Similarly, with others there was a realisation that talking could relieve stress through everyday conversations that provided a sense of 'normality', or a distraction from their care-giving role:

Talking to people is a wonderful thing. It relieves a lot of stress from the person because you don't necessarily have to talk about the difficulties at home. You can talk about everything else and during that time that you're talking about other things you forget about the situation. Just talking to somebody and not talk about what's going on in the house, talk about football or something. (Simon)

Most references about talking to someone referred to a one-to-one scenario, and no participants spoke about group situations apart from one who highlighted the benefit of attending a carer support group. This group was facilitated by the day centre attended by his wife, and it provided a welcome social opportunity, along with the chance to come together with others similar to himself: 
I regard that meeting as the highlight of my month, because it's a wee bit of social occasion, and its tea and biscuits, or something like that, just for kindness. The rapport between everybody is fantastic. It's really good. (Tim)

Another way to relieve care-giving stress as described by some participants was use of prescribed medication such as antidepressants. Colin reflected on how he relied on this medication to keep going and how he would most likely be taking antidepressants for the rest of his life. However, explaining the use of antidepressants as a coping strategy to a friend resulted in ostracism:

A friend of mine ... this fella that knows me pretty well, a lot of months ago he says to me, 'Colin - how are you keeping, yourself?', and I said, 'Billy I'm dead on', but I wasn't telling him really the honest truth, 'see only for them antidepressants, I couldn't cope'. He looked at me and says 'Colin - a big strong guy like you needing antidepressants?' I didn't make any comment because you don't know unless you're living with it. (Colin)

Colin's friend had interpreted the reliance on antidepressants as a sign of weakness. Thus, Colin's masculine identity was potentially compromised-not only by expressing difficulty in coping with his care-giving role, but also through admitting to his friend that he was taking antidepressants (i.e. peer pressure to be a 'strong man').

Another participant, who had come from a medical background, was considering taking antidepressants for some time, but only 'relented' when his family put pressure on him, as described:

Emotionally, I was a shambles, I relented and my children were after me to go and get an antidepressant and I did and went and saw my GP [general practitioner] ... I can talk about my emotions without becoming emotional. (Ian)

The experience of using prescribed medication was also mentioned by Gerry. Although initially fearing that care-giving may be too difficult, Gerry felt committed to his spouse, and antidepressants enabled him to continue with his care-giving role:

There would have been stages there where I thought I'd bit off more than I can chew if you know what I mean by that? But, I sort of, mentally speaking I'd committed to I can do this, you know this way? It's just going to take time, so to speak and it did, then, I don't know, maybe I was on medication for a year and a half. (Gerry)

\section{Discussion}

Analysis of data revealed three overarching themes: dwindling social interactions, loneliness in the spousal relationship, and living with loneliness and social isolation.

Previous evidence has indicated that loneliness is a distinct problem for caregivers (Vasileiou et al., 2017; Gray et al., 2020), and more specifically for older caregivers, male and female alike (Courtin and Knapp, 2017; Greenwood et al., 2019). 
However, gender-based differences in the experience of care-giver loneliness is becoming increasingly acknowledged (Nel and Board, 2019; Willis et al., 2020; Victor et al., 2020). Specifically, it has been asserted that although male and female care-givers may have similar care-giving experiences, older male care-givers experience increased social isolation and loneliness as a result of declining social networks and opportunities for sociability (Milligan and Morbey, 2016).

In line with previous literature (Simpson et al., 2018), findings of the current study indicated that a sense of dwindling social opportunities was predominant amongst older male care-givers. This appeared to be the result of participants becoming more housebound due to a fear of leaving their spouse/partner on her own or friends gradually dropping away. Participants described a new reality whereby many had to navigate an uncertain trajectory, often without the social support or spousal companionship that they once enjoyed. These findings were consistent with other studies, such as Simpson et al. (2018) who explored the experiences of loneliness in older husband dementia care-givers in the United States of America $(\mathrm{N}=6)$. Simpson et al. found that male care-givers experienced multiple losses, including loss of their wives as well as their friends and social contacts. When friends stopped visiting, male care-givers felt abandoned and isolated.

Several participants in the current study described challenges and frustration with their situation, which for one resulted in consideration of placement to longterm residential care, and for another consideration of 'living apart'. Given the complexity of these men's situations, the foundation of these feelings cannot be determined. However, previous care-giving literature has linked spousal loneliness with the quality of the marital relationship (Stokes, 2017; Willis et al., 2020; Victor et al., 2020). Willis et al. (2020) speculated that experiences of loneliness may be 'relationship specific', that is - if the quality of the relationship deteriorates or the care recipient's illness progresses, then there was potential for loneliness.

One of the most sought-after relationships to address loneliness amongst older people are those based on closeness and intimacy (Cohen-Mansfield and Eisner, 2020), therefore it could be argued that the perceived loss of the close spousal relationship experienced by older spousal male care-givers in the current study exacerbated their loneliness. Rykkje and Tranvåg (2019) explored older husband's experiences of caring for their wives in Norway $(\mathrm{N}=5)$, and revealed that a decline in mutual interests led to a sense of loneliness for study participants, often underpinning their choice of actions. For example, some husbands chose to stop pursuing mutual interests (such as going to the theatre) after their wife's interest faded.

This loss of meaningful interaction and shared interests was echoed by Nel and Board (2019) in a review of older husbands caring for their wives with dementia in the UK. Nel and Board emphasised that although loss of companionship was prevalent in their studies and often resulted in loneliness, resilience was often reflected through devotion and commitment shown to wives. Although there was some evidence of this in the current study, as described by Mike, Andy and Tim (in Theme 2), it could be argued that resilience which is brought about by love and devotion may be limited to the time when the care recipient's illness is in the early stages. This was reflected in a qualitative exploration of loneliness and social isolation of older male care-givers in the UK $(\mathrm{N}=25)$. In this, Willis et al. (2020) found that older male care-givers experienced their care-giving role as a 
buffer against loneliness, due to the presence of the care recipient. However, study participants acknowledged that when the chronic illness progressed, they could potentially experience loneliness. Furthermore, consistent with findings from previous studies, such as Vasileiou et al. (2017), some evidence in the current study suggests that even whilst in the company of others male care-givers may still experience loneliness and feel isolated. For example, Dan's description of his fear when someone else wanted to take his wife to the toilet illustrated how loneliness was expressed within current social activities, and was characterised as a lack of understanding within the actions of (often well-meaning) friends.

\section{Masculinity and older male care-givers}

Some previous literature links a reluctance to seek psychological help with their older men's views on traditional 'hegemonic' masculinity (Vogel et al., 2011; Addis and Hoffman, 2017; Seidler et al., 2017). Traditional masculine behaviour has been characterised as independent, stoic and self-reliant (Connell and Messerschmidt, 2005). Conformity to such traditional masculine ideals is difficult for some men due to the restrictive nature of these norms when navigating family and social life. In the care-giving literature, it has been argued that care-giving can pose a conflict for some males as it is often viewed as 'unmasculine' by society (Milligan and Morbey, 2016).

Findings in the current study suggested that men took a protective approach to their spouse and expressed a preference for independence within their care-giving role, thus decreasing their likelihood of accepting support. This resonated with findings from a UK study by Ratcliffe et al. (2021), who asserted that in order to provide actions of care and responsibility to family members, men's masculine identity could be 'reformed' so that care acts could be seen as 'morally congratulable'. This appeared to enable men to feel a sense of pride as it was consistent with masculine norms of strength and reliability. Ratcliffe's study further revealed that identification with masculine ideology resulted in a reluctance to admit to loneliness, despite reports of social isolation. Additionally, McKenzie et al. (2018) concluded that masculine ideologies potentially dictated the nature of close relationships. According to McKenzie, some men could be hesitant to form close social relationships with other men for fear of it being viewed as homosexual (incompatible with hegemonic masculinity), resulting in a heavier reliance on women in private for emotional support, and restricting opportunities for social support during times of stress.

\section{Supportive interventions for older male care-givers}

Although findings in the current study revealed strategies employed by participants to help mitigate feelings of loneliness, there was no obvious use of formal interventions to combat loneliness or social isolation. This could be either because participants believed that no formal support was available for them, or because they did not think that existing formal support interventions were suitable for their particular needs. 
In the current study, several participants referred to benefits of having someone to talk to and 'offload'. However, it was observed that this was a highly individualised strategy, with participants describing a number of different circumstances within which they benefited by talking to someone, including finding an 'auntie' to talk to, talking about football as a distraction from the 'difficulties at home', or a local carer support group. This has also been observed in other literature. Fakoya et al. (2020) emphasised individuality of the experience of loneliness and social isolation within the older population. This meant that often the delivery of 'standardised interventions' to combat loneliness (such as counselling, education, befriending or technology/telephone support) was difficult and ineffective.

Social isolation has been described as an 'emerging crisis' for older men in the UK, due to demographic changes and lack of support services to meet the 'unique needs of older men' (Beach and Bamford, 2015). Previous research highlighting men's reluctance to seek psychological support and the 'invisibility' of the gendered nature of men's mental health in literature (Seidler et al., 2018) has underpinned the need to develop gender-based support initiatives that target men. There is only limited research about interventions that target loneliness and social isolation among older males (Poscia et al., 2017). However, there have been some promising results from current male-centred initiatives, such as Men's Sheds - which originated in Australia, and is now common in other countries, including the UK and Ireland. This initiative aims to decrease social isolation and improve older men's mental wellbeing through men-centred social interaction (Hlambelo, 2015). A review of Men's Sheds by Hlambelo (2015) demonstrated improvements in men's physical and mental wellbeing through participation in meaningful male-specific activities, in a male-centred environment. These findings align with previous work emphasising that to engage men in psychological support, gendered expectations and societal pressures on men must be recognised (Pirkis et al., 2019; Seidler et al., 2018). Moreover, although male care-givers have been found to be reluctant to accept psychological support (Milligan and Morbey, 2013; Judd et al., 2018), they will accept support if they can do so whilst maintaining autonomy (Spendelow et al., 2017), and if the support is set within a male-centred environment (Fee et al., 2020b; Willis et al., 2020).

The global pandemic, Coronavirus (COVID-19), has placed additional strain and responsibility not only on health-care systems world-wide, but also on family care-givers. International evidence suggests that the outbreak of COVID-19 has elevated levels of care-giver stress, and amplified social isolation for care-givers due to suspension of local support services (Alzheimer's Association, 2020; Cohen et al., 2020; Gallagher and Wetherell, 2020; Hwang et al., 2020). A need to develop tailored formal interventions to target loneliness and social isolation amongst older people has been identified (Fakoya et al., 2020); and is especially important within 'at-risk' sub-groups (such as older male care-givers) (Courtin and Knapp, 2017). Thus, now more than ever, a need exists to identify support needs to combat loneliness and social isolation amongst older male caregivers, and to provide support that enables this population to sustain their caregiving role. 


\section{Study limitations}

A number of limitations of this study are noted. Firstly, given that the study sample was recruited through support agencies, it is possible that the care-givers may be (or were previously) in receipt of some form of formal support. Thus, the voices of care-givers who were unsupported or totally unaware of services are missing. Secondly, although the majority of participants were dementia care-givers $(\mathrm{N}=16)$, the sample also included participants providing care for partners with other conditions (stroke, epilepsy, multiple sclerosis, and Parkinson's disease). Although this composition is reflective of the prevalence of dementia in western society, it is also noted that care-givers were coping with a broad range of illness symptoms, at different stages of the illness trajectory. This would undoubtedly have impacted on their care-giving experiences. Also, the sample of white males within heterosexual relationships lacked diversity, which may have had a bearing on the findings. The study adopted a qualitative approach and, as such, the generalisability of the findings are limited. However, a qualitative approach afforded the depth of data that is required to investigate this phenomenon (Parahoo, 2014). Finally, there is considerable variation in the socio-demographic profile of caregivers, specifically age. It is noted that while all but one of the participants were 'older' (i.e. above 65), factors that influence the 'oldest old' (Greenwood and Smith, 2016) (i.e. care-givers aged over 75) may not have been considered in the data analysis.

\section{Conclusion}

Loneliness and social isolation among older care-givers are becoming increasingly recognised and pose challenges for public health, and health and social care policy and practice. Older male spousal care-givers especially are vulnerable to loneliness and social isolation. It has been asserted that older males rely more on their spouse for emotional support than older females. Consequently, when spousal support declines through chronic illness, loneliness may be compounded for older male care-givers. However, little is known about how to address loneliness and social isolation in this population.

Findings of the present study suggest that opportunities for social interactions gradually 'dwindled' due to a reluctance by older male care-givers to leave their spouse/partner at home alone, to accept offers of help or respite, or to attend social events without their partner. Consequently, study participants felt increasingly socially isolated. Whilst for some participants, there was evidence of gratitude for the company of their spouse/partner; for others, feelings of physical and emotional loneliness were evident, and the loss of spousal companionship (such as loss of conversation and shared interests) increased loneliness. Individualised coping strategies were adopted, including focusing on moments of positivity, talking to others and using prescribed medication.

Given the increasing numbers of older male care-givers and suggestions that support needs of this population are neglected (Sharma et al., 2016), it is important to identify factors that contribute to loneliness and social isolation. Findings of the present study provide insight into the experience of loneliness and social isolation for some older male spousal care-givers. As such, it is anticipated that this may 
facilitate a better understanding of older male care-givers' support needs and contribute towards the development of sustainable support for this population group.

Acknowledgements. The authors wish to acknowledge the male care-givers who gave up their time to be interviewed for this study.

\section{Author contributions.}

All authors (AF, SMcI, AR) made substantial intellectual contributions to the manuscript. AF was involved in collecting data; AF undertook data analysis, supported by AR. All authors contributed to drafting the manuscript, revising it critically for intellectual content and gave final approval of the version to be published.

Financial support. This work was supported by the HSC Research \& Development Division, Northern Ireland Public Health Agency, UK (EAT/5216/15). The financial sponsors played no role in the design, execution, analysis and interpretation of data, or writing of the study.

Conflict of interest. The authors declare no conflicts of interest.

Ethical standards. The study was granted ethical approval from OREC (UK) (REC reference 17/WM/ 0019), Ulster University School of Nursing, Research Ethics Committee (reference 17/0021) and the Northern Health and Social Care Trust (governance approval NT 17-0558-04).

\section{References}

Addis M and Hoffman E (2017) Men's depression and help-seeking through the lenses of gender. In Levant R and Wong J (eds), The Psychology of Men and Masculinities. Washington, DC: American Psychological Association, pp. 171-196.

Age UK (2018) All the Lonely People: Loneliness in Later Life Report. Available at https://www.ageuk.org.uk/ globalassets/age-uk/documents/reports-and-publications/reports-and-briefings/loneliness/lonelinessreport.pdf.

Alzheimer's Association (2020) 2020 Alzheimer's disease facts and figures. Alzheimer's \& Dementia 16, 32-44.

Beach B and Bamford S (2015) Isolation: The Emerging Crisis for Older Men. London: Independent Age. Available at https://independent-age-assets.s3.eu-west-1.amazonaws.com/s3fs-public/2016-05/isolationthe-emerging-crisis-for-older-men-report.pdf.

Braun V and Clarke V (2006) Using thematic analysis in psychology. Qualitative Research in Psychology 3, 77-101.

Brodsky J, Shnoor Y and Be'er S (2017) The 65+ Population in Israel: Statistical Abstract 2016. Jerusalem: Myers-JDC-Brookdale.

Bryman A (2015) Social Research Methods, 5th Edn. Oxford: Oxford University Press.

Cohen-Mansfield J and Eisner R (2020) The meanings of loneliness for older persons. Aging \& Mental Health 24, 564-574.

Cohen-Mansfield J, Hazan H, Lerman Y and Shalom V (2016) Correlates and predictors of loneliness in older-adults: a review of quantitative results informed by qualitative insights. International Psychogeriatrics 28, 557-576.

Cohen G, Russo M, Campos J and Allergi R (2020) Living with dementia: increased level of caregiver stress in times of COVID-19. International Psychogeriatrics 32, 1377-1381.

Connell RW and Messerschmidt JW (2005) Hegemonic masculinity: rethinking the concept. Gender \& Society 19, 829-859.

Cotterell N, Buffel T and Phillipson C (2018) Preventing social isolation in older people Maturitas 113, 80-84.

Courtin E and Knapp M (2017) Social isolation, loneliness and health in old age: a scoping review. Health \& Social Care in the Community 25, 799-812.

De Jong Gierveld J, Van Tilburg T and Dykstra P (2006) Loneliness and social isolation. In Vangelisti A and Perlman D (eds), The Cambridge Handbook of Personal Relationships. Cambridge Handbooks in Psychology. Cambridge: Cambridge University Press, pp. 485-500. 
Dickinson C, Dow J, Gibson G, Hayes L, Robalino S and Robinson L (2017) Psychosocial intervention for carers of people with dementia: what components are most effective and when? A systematic review of systematic reviews. International Psychogeriatrics 29, 31-43.

Fakoya OA, McCorry NK and Donnelly M (2020) Loneliness and social isolation interventions for older adults: a scoping review of reviews. BMC Public Health 20, 129.

Family Caregiver Alliance (2019) Caregiver Statistics: Demographics. Available at https://www.caregiver. org/caregiver-statistics-demographics.

Fee A, Mcllfatrick S and Ryan A (2020a) An Exploration of the Impact of Support Services in Identifying and Meeting the Needs of Older Male Caregivers Caring for a Chronically Ill Spouse/Partner. Available at https://research.hscni.net/sites/default/files/Meeting\%20the\%20support\%20needs\%20of\%20older\% 20male\%20caregiviers_Final\%20Report_AFee2020.pdf.

Fee A, McIlfatrick S and Ryan A (2020b) Examining the support needs of older male spousal caregivers of people with a long-term condition. A systematic review of the literature. International Journal of Older People Nursing 15, e12318.

Finlay JM and Kobayashi LC (2018) Social isolation and loneliness in later life: a parallel convergent mixed-methods case study of older adults and their residential contexts in the Minneapolis metropolitan area, USA. Social Science \& Medicine 208, 25-33.

Gale CR, Westbury L and Cooper C (2017) Social isolation and loneliness as risk factors for the progression of frailty: the English Longitudinal Study of Ageing. Age and Ageing 47, 392-397.

Gallagher S and Wetherell M (2020) Risk of depression in family caregivers. Unintended consequence of COVID-19. BJPsych Open 6, E119.

Gray TF, Azizoddin DR and Nersesian PV (2020) Loneliness among cancer caregivers: a narrative review. Palliative and Supportive Care 18, 359-367.

Greenwood N and Smith R (2016) The oldest carers: a narrative review and synthesis of the experiences of carers aged over 75 years. Maturitas 94, 161-172.

Greenwood N, Pound C, Brearley S and Smith R (2019) A qualitative study of older informal carers' experiences and perceptions of their caring role. Maturitas 124, 1-7.

Hansen T and Slagsvold B (2016) Late-life loneliness in 11 European countries: results from the generations and gender survey. Social Indicators Research 129, 445-464.

Hlambelo L (2015) Impact of Men's Sheds on the Health and Wellbeing of the Men Involved: A Biopsychosocial Study (PhD thesis). Western Sydney University. Available at https://researchdirect. westernsydney.edu.au/islandora/object/uws\%3A36955/datastream/PDF/download/citation.pdf.

Holt-Lunstad J, Smith TB, Baker M, Harris T and Stephenson D (2015) Loneliness and social isolation as risk factors for mortality: a meta-analytic review. Perspectives on Psychological Science 10, 227-237.

Hwang T, Rabheru K, Peisah C, Reichman W and Ikeda M (2020) Loneliness and social isolation during COVID-19 pandemic. International Psychogeriatrics 32, 1217-1220.

Independent Age and the International Longevity Centre UK (2014) Isolation: The Emerging Crisis for Older Men. A Report Exploring Experiences of Social Isolation and Loneliness Among Older Men in England. Available at https://www.independentage.org/news-media/press-releases/isolation-emergingcrisis-for-older-men.

Judd R, Guy H and Howard RA (2018) Caring for a dying partner: the male experience. Journal of Palliative Care 34, 5-11.

Kuiper JS, Zuidersma M, Voshaar RCO, Zuidema SU, van den Heuvel ER and Stolk RP (2015) Social relationships and risk of dementia: a systematic review and meta-analysis of longitudinal cohort studies. Ageing Research Reviews 22, 39-57.

Lincoln YS and Guba EG (1985) Naturalistic Inquiry. Newbury Park, CA: Sage.

Matthews GA, Nieh EH, Vander CM, Weele SA, Halbert RV, Pradhan AS and Yosafat AS (2016) Dorsal raphe dopamine neurons represent the experience of social isolation. Cell 164, 617-631.

McKenzie SK, Collings S, Jenkin G and River J (2018) Masculinity, social connectedness, and mental health: men's diverse patterns of practice. American Journal of Men's Health 12, 1247-1261.

Milligan C and Morbey H (2013) Older Men Who Care: Understanding Their Support and Support Needs. Lancaster University Centre for Ageing Research. Available at https:/eprints.lancs.ac.uk/id/eprint/68443/ 1/Older_men_who_care_report_2013Final.pdf.

Milligan C and Morbey H (2016) Care, coping and identity: older men's experiences of spousal caregiving. Journal of Aging Studies 38, 105-114. 
Nel K and Board M (2019) What is an older husband's experience of caring for his wife who has dementia? Nursing Older People 31, 22-27.

Parahoo K (2014) Nursing Research Principles, Process and Issues, 3rd Edn. Basingstoke, UK: Palgrave Macmillan.

Phillips D, Paul G, Fahy M, Dowling-Hetherington L, Kroll T, Moloney B, Duffy C, Fealy G and Lafferty A (2020) The invisible workforce during the COVID-19 pandemic: family carers at the frontline. HRB Open Research 3, 24.

Pirkis J, Schlichthorst M, King K, Lockley A, Keogh L, Reifels L, Spittal MJ and Phelps A (2019) Looking for the 'active ingredients' in a men's mental health promotion intervention. Advances in Mental Health 17, 135-145.

Poscia A, Stojanovic J, La Milia DI, Duplaga M, Grysztar M, Moscato U, Onder G, Collamati A, Ricciard W and Magnivita N (2017) Interventions targeting loneliness and social isolation among the older people: an update systematic review. Experimental Gerontology 102, 133-144.

Quinn-Patton M (2002) Two decades of developments in qualitative inquiry. A personal experiential perspective. Qualitative Social Work 1, 261-283.

Ratcliffe J, Wigfield A and Alden S (2021) 'A lonely old man': empirical investigations of older men and loneliness, and the ramifications for policy and practice. Ageing \& Society 41, 794-814.

Rico-Uribe LA, Caballero FF, Martín-María N, Cabello M, Ayuso-Mateos JL and Miret M (2018) Association of loneliness with all-cause mortality: a meta-analysis. PLOS ONE 13, e0190033.

Rykkje L and Tranvåg O (2019) Caring for one's wife with dementia - at home: older husbands' experiences with managing challenges of everyday life. SAGE Open 9. Available at https://doi.org/10.1177/ 2158244019834453.

Schwartz AJ and McInnis-Dittrich K (2015) Meeting the needs of male caregivers by increasing access to accountable care organizations. Journal of Gerontological Social Work 58, 655-670.

Seidler ZE, Rice S, River J, Oliffe J and Dhillon HM (2017) Men's mental health: a case for a masculinities model. Journal of Men's Studies 26, 92-104.

Seidler ZE, Rice SM, Ogrodniczuk JS, Oliffe JL and Dhillon HM (2018) Engaging men in psychological treatment: a scoping review. American Journal of Men's Health 12, 1882-1900.

Sharma N, Chakrabarti S and Grover S (2016) Gender differences in caregiving among family - caregivers of people with mental illnesses. World Journal of Psychiatry 6, 7-17.

Silverman D (2004) Qualitative Research: Theory, Method and Practice. London: Sage.

Simpson GM, Stansbury K, Wilks SE, Pressley T, Parker M and McDougall GJ (2018) Support groups for Alzheimer's caregivers: creating our own space in uncertain times. Social Work in Mental Health 16, 303-320.

Spendelow JS, Adam LA and Fairhurst BR (2017) Coping and adjustment in informal male carers: a systematic review of qualitative studies. Psychology of Men and Masculinities 18, 134-143.

Steptoe A, Shankar A, Demakakos P and Wardle J (2013) Social isolation, loneliness, and all-cause mortality in older men and women. Proceedings of the National Academy of Sciences of the United States of America 110, 5797-5801.

Stokes JE (2017) Two-wave dyadic analysis of marital quality and loneliness in later life: results from the Irish Longitudinal Study on Ageing. Research on Aging 39, 635-656.

Valtorta NK, Kanaan M, Gilbody S, Ronzi B and Hanratty B (2016) Loneliness and social isolation as risk factors for coronary heart disease and stroke: systematic review and meta-analysis of longitudinal observational studies. Heart 102, 1009-1016.

Vasileiou K, Barnett J, Barreto M, Vines J, Atkinson M, Lawson S and Wilson M (2017) Experiences of loneliness associated with being an informal caregiver: a qualitative investigation. Frontiers in Psychology 8, 585.

Victor CR, Rippon I, Quinn C, Nelis SM, Martyr A, Hart N, Lamont R and Clareon L (2020) The prevalence and predictors of loneliness in caregivers of people with dementia: findings from the IDEAL programme. Aging \& Mental Health. Available online doi:10.1080/13607863.2020.1753014.

Vogel D, Heimerdinger-Edwards S, Hammer J and Hubbard A (2011) 'Boys don't cry': examination of the links between endorsement of masculine norms, self-stigma, and help-seeking attitudes for men from diverse backgrounds. Journal of Counseling Psychology 58, 368-382. 
Willis P, Vickery A and Symonds J (2020) 'You have got to get off your backside; otherwise, you'll never get out': older male carers' experiences of loneliness and social isolation. International Journal of Care and Caring 4, 311-330.

World Health Organization (2014) Health Statistics and Health Information Systems. Geneva: World Health Organization. Available at http://www.who.int/healthinfo/survey/ageingdefnolder/en/.

Yang YC, McClintock MK, Kozloski M and Li T (2013) Social isolation and adult mortality: the role of chronic inflammation and sex differences. Journal of Health and Social Behavior 54, 183-203.

Zebhauser A, Hofmann-Xu L, Baumert J, Häfner S, Lacruz ME, Emeny RT, Döring A, Grill E, Huber D, Peters A and Ladwig KH (2014) How much does it hurt to be lonely? Mental and physical differences between older men and women in the KORA-Age Study. International Journal of Geriatric Psychiatry 29, 245-252.

Cite this article: Fee A, McIlfatrick S, Ryan A (2021). 'The care circle consists of me.' Loneliness and social isolation for older male spousal care-givers. A qualitative study. Ageing \& Society 1-18. https://doi.org/ $10.1017 / \mathrm{S} 0144686 \mathrm{X} 21000854$ 